\title{
Ethanol challenge in non-alcoholic patients with schistosomiasis
}

\author{
R D Martins, D R Borges
}

\begin{abstract}
Aims: To evaluate serum $\gamma$ glutamyltransferase (GGT) activity in a group of non-alcoholic patients with the hepatointestinal form of schistosomiasis; and the response of both GGT and alkaline phosphatase to an ethanol challenge in two subgroups of patients with different baseline serum concentrations of GGT.

Methods: Seventy six non-alcoholic, nonsmoking hepatitis B virus (HBV) negative men with normal body mass index, who denied blood product transfusion or use of medication, were studied (30 healthy volunteers (control group) and 46 patients with the hepatointestinal form of schistosomiasis). GGT activities were determined in all subjects and the ethanol test (measurement of GGT and alkaline phosphatase (ALP) before and 24 hours after the ingestion of $1 \mathrm{~g} / \mathrm{kg}$ of ethanol) was performed in 14 patients ( 7 with GGT below 25 IU/I and seven with GGT above 25 IU/I). The ethanol serum concentrations were determined in the samples collected one hour after ingestion of the solution in four patients with schistosomiasis.
\end{abstract}

Results: The mean serum ethanol concentration one hour after the ingestion was $0.7 \mathrm{~g} / \mathrm{l}$ and all patients were clinically intoxicated. GGT was below 25 IUn in all 30 volunteers and in 33 of the patients with schistosomiasis. In 13 patients the GGT varied from 28 to $140 \mathrm{IU} / \mathrm{h}$. The two enzymes GGT and ALP determined in the 14 patients submitted to the test were positively correlated in the baseline samples $(r=0.8130)$ as well as in the samples obtained 24 hours after stimulation $(r=0.7921)$. Neither the plasma activity of GGT nor the GGT:ALP ratio was affected by the ethanol challenge.

Conclusions: These results suggest that the mechanisms for the increase of GGT serum activity in schistosomiasis and in alcoholism differ. In the latter, microsomal induction increases GGT serum activity, while alterations in the biliary tree may be responsible for the increase observed in patients with schistosomosiasis.

\section{(F Clin Pathol 1993;46:250-253)}

Affecting more than 200 million people, schistosomiasis is the most common cause of liver disease in man. $^{1}$ The last survey on the prevalence of schistosomiasis in Brazil shows that transmission of the diseases occurs in $11 \%$ of the national territory, and it is estimated that there are 6-8 million people infected. Most of the patients with schistosomiasis (90-95\%) evolve to a mild chronic form, also called hepatintestinal schistosomiasis, characterised by the presence of scattered granulomas in the liver and by partial fibrosis. The initial parasite burden and the host's immune response determine the evolution of the remaining $5-10 \%$ to the advanced chronic form, characterised by a massive periportal fibrosis (Symmers's fibrosis). ${ }^{2}$

The functional evaluation of the liver in schistosomiasis has not yet been regulated, and most studies with such patients have not clearly excluded alcoholics and hepatotropic virus carriers. Grouping of patients with schistosomiasis according to the Child-Pugh criterion $^{3}$ is inadequate, as the liver parenchyma remains preserved even in the more advanced forms and most patients would be classified as being in the Child-Pugh A group. Changes in the metabolism of cholylglycine, ${ }^{4}$ bromsulphalein, ${ }^{5}$ and antipyrine ${ }^{6}$ can reflect the deviation of the blood flow by collateral circulation rather than a dysfunction of the parenchyma liver cells. In these patients a decrease in the protein plasma concentrations of the coagulation or anticoagulation systems can be interpreted as a liver deficiency in synthesis or chronic consumption coagulopathy. ${ }^{78}$

Besides the functional evaluation, raised serum enzyme activities used in clinical practice for the detection of hepatic aggression have been reported in the chronic parasitosis forms, but the mechanism responsible for these alterations is not yet clear. Although liver schistosomiasis is not characterised by the presence of cholestasis, an increase in $\gamma$ glutamyl transferase (GGT) occurs more often than transaminases in these patients.

Serum $\gamma$ glutamyl transferase activities vary according to the sex, age, weight and smoking habits of the population being studied. Diagnostic specificity is limited because GGT activity may increase in several liver diseases. ${ }^{10}$ Better specificity is achieved when such activities are evaluated with those of alkaline phosphatase (ALP), as both increase in a parallel manner in cholestasis. An increase of GGT disproportionately higher than that of ALP is a strong suggestion of alcohol abuse even when histological changes are absent. ${ }^{11}$

Application of an ethanol challenge to 
groups of moderate drinkers (60 to $80 \mathrm{~g}$ /ethanol/day) with normal liver histology after a four week abstinence produced a significant increase in serum GGT activity with a zenith at 24 hours $^{12}$.

The aim of this work was to evaluate GGT in a uniform group of patients with a hepatintestinal form of schistosomiasis, free from other factors that could injure the liver, and to evaluate the GGT and ALP response to the ethanol test in two subgroups of patients with different baseline GGT serum activities.

\section{Methods}

The series comprised 76 patients attending the outpatients at the Clinical Gastroenterology Division, Escola Paulista de Medicina, São Paulo. To obtain a uniform group we included adult males with a relatively normal weight (23-26 kg/m $\mathrm{m}^{2}$, who denied habitual alcohol consumption (anamnesis and CAGE questionnaire), smoking, prior blood transfusion, regular use of drugs but who were negative for $\mathrm{HBV}$ serology (radioimmunoassay for $\mathrm{HBsAg}$, anti-HBc, and anti-HBs).

These 76 subjects were divided into two groups: a control group of 30 healthy subjects, aged between 21 and 34 years; and a schistosomiasis group of 46 patients with the hepatintestinal form, aged between 19 and 34 years, the diagnosis being established by presence of Schistosoma mansoni in the stools. The liver was not palpable $3 \mathrm{~cm}$ from the right costal margin or the xiphoid appendage in any of the patients; spleen was not noted to be enlarged by percussion or palpation.

Determinations of $\gamma$-glutamyl transferase and alkaline phosphatase activities were determined immediately after the serum was obtained, at $37^{\circ} \mathrm{C}$, in duplicate, by methods based on the recommendations of the German Society for Clinical Chemistry (Merck SA; catalogue No 125.939 for $\gamma$-glutamyl transferase and No 14316 for alkaline phosphatase). The ethanol test was performed as described by Nemesanszki et $a l^{12}$ in 14 patients: seven with GGT of $<25 \mathrm{IU} / 1$ and seven with GGT of $>25 \mathrm{IU} / \mathrm{l}$. We collected baseline blood samples and further samples 24 hours after a $10 \%$ ethanol solution had been ingested with orange juice (dose: $1 \mathrm{~g}$ ethanol/ $\mathrm{kg}$ body weight in a one hour period) to determine GGT and ALP values. The serum ethanol concentrations were determined in the samples collected one hour after ingestion of the solution (Merck; catalogue No 123960). Additionally, the ethanol test was given to two alcoholics (intake of $100 \mathrm{~g} / \mathrm{ethanol} \mathrm{for} \mathrm{five} \mathrm{years} \mathrm{at} \mathrm{least).}$

Table 1 GGT and ALP basal values and values after ethanol challenge in both groups (mean $(S D)$ )

\begin{tabular}{llllllll}
\hline & \multicolumn{3}{l}{$G G T$ IU/l } & & & ALP (IU/l) \\
\cline { 2 - 4 } Subgroup & Basal & After & Paired $t$ test & & Basal & After & Paired t test \\
\hline GGT $<25$ & $14(7)$ & $18(6)$ & $\mathrm{p}>0.05$ & & $135(75)$ & $140(63)$ & $\mathrm{p}>0.05$ \\
GGT $>25$ & $65(18)$ & $63(35)$ & $\mathrm{p}>0.05$ & & $279(110)$ & $272(115)$ & $\mathrm{p}>0.05$ \\
\hline
\end{tabular}

\section{Results}

GGT ranged from 4-22 IU/1 in the control group, the average (SD) being $10.6(4 \cdot 8) \mathrm{IU} / \mathrm{l}$; in the schistosomiasis group it ranged from 4-140 IU/1, the average (SD) being $25 \cdot 6(28 \cdot 1)$ IU/1. These averages were significantly different when compared by the $t$ test. In spite of this difference the calculated Overlap Index ${ }^{13}$ was 0.66 , revealing a significant overlap of the GGT values in the control and schistosomiasis groups. This shows that GGT had a low sensitivity for the discrimination between the schistosomiasis group and the control group.

If a figure corresponding to three standard deviations is added to the average of the control group we obtain $25 \mathrm{IU} / 1$. No subject in the control group had a GGT of $>25$ IU/l, while 13 patients in the schistosomiasis group had a GGT higher than this (Table 1). The distribution of GGT values of < or > 25 IU/ 1 in the two groups was significantly different $\left(\mathrm{p}<0.05 ; \chi^{2}\right)$. The 25 IU/1 value discriminated the schistosomiasis group with $28 \%$ sensitivity and $100 \%$ specificity.

We formed two subgroups using $25 \mathrm{IU} / 1$ as the cutoff: patients with schistosomiasis and a GGT of $<25 \mathrm{IU} / 1$ or with a GGT of $>25 \mathrm{IU} /$ 1. In each subgroup seven patients took the ethanol test. After drinking orange juice containing ethanol, all the patients presented clinical signs of acute alcoholic intoxication. Dosed one hour later in four schistosomiasis patients (two in each subgroup), the average serum ethanol concentration was $0.7 \mathrm{~g} / 1$.

We also determined the ALP values in the 14 patients who took the test. Analysed by the Mann-Whitney $U$ test, GGT and ALP presented a positive correlation in the baseline samples as well as in the samples obtained 24 hours after stimulation. The correlation coefficients between GGT and ALP values were $r=0.8130 \quad(p<0.01)$ and $r=0.7921$ $(p<0.01)$ at basal and 24 hours after challenge, respectively. Table 2 shows that the GGT:ALP ratio was not altered by the ethanol challenge. In the alcoholic patient with a basal high GGT value (251 IU/l), the ethanol challenge did not alter the serum GGT value (231 IU/1), while in the alcoholic patient with a basal GGT of $45 \mathrm{IU} / 1$ increased to $106 \mathrm{IU} / 1$ after the challenge.

\section{Discussion}

We selected a uniform group for this study to minimise the possibility that other causes over and above schistosomiasis might also be responsible for the increase in the serum GGT and ALP values, which would make inter-

Table 2 GGT:ALP ratio basal values and values afier ethanol challenge (mean (SD))

\begin{tabular}{|c|c|c|c|c|}
\hline \multirow[b]{2}{*}{ Subgroup } & \multirow[b]{2}{*}{$n=$} & \multicolumn{3}{|l|}{ Ratio } \\
\hline & & Basal & After & paired $t$ test \\
\hline $\begin{array}{l}\text { GGT }<25 \\
\mathrm{IU} / 1\end{array}$ & 7 & $0.13(0.09)$ & $0.15(0.07)$ & $p>0.05$ \\
\hline $\begin{array}{l}\text { GGT > } 25 \\
\text { IU/1 }\end{array}$ & 7 & $0.24(0.10)$ & $0.24(0.11)$ & $p>0.05$ \\
\hline
\end{tabular}


pretation of the results more difficult. Because of the inclusion criteria, serum GGT did not attain $25 \mathrm{IU} / 1$ in any subject in the control group. The adopted cutoff discriminated 13 $(28 \%)$ of the 46 patients in the schistosomiasis group: six patients had a serum activity above $2 \mathrm{~N}$ (N: upper limit of the reference range) and the maximum value was $140 \mathrm{IU} / 1$.

The GGT increase in alcoholics has been intensively studied. Acute intoxication by ethanol does not alter the serum GGT values or that of other enzymes in healthy, non-alcoholic volunteers. ${ }^{14}$ Prolonged ethanol ingestion causes ultrastructural alterations in the livers of healthy and non-alcoholic subjects after four weeks of taking $63 \mathrm{~g}$ of ethanol daily, but serum GGT only increased after the fifth week. ${ }^{15}$ Acute intoxication in alcoholics with persistently high GGT does not increase its serum activity further. ${ }^{16}$ This behaviour was observed in one of the alcoholic patients tested.

In alcoholics with no clinical signs of liver disease, the four week abstinence from alcohol renders GGT serum activity normal in $80 \%$ of cases, while in those patients with evident liver disease GGT remains high even after eight weeks of abstinence. ${ }^{17}$ In the group of moderate alcoholics studied by Nemesanszki et $a l^{12}$ the four week abstinence rendered serum GGT activities normal. After this, even in the absence of morphological lesion, acute ethanol load enhanced serum activity of GGT, probably reflecting hepatic enzyme induction. This behaviour was observed in the other alcoholic patient studied.

Chronic ethanol ingestion results in the proliferation of the smooth endoplasmic reticulum of hepatocytes associated with the induction of several microsomal enzymes, including those of the ethanol oxidation microsomal system (MEOS). Chronic MEOS stimulation can cause the induction and liberation of GGT from the hepatocyte microsomal fraction, thus explaining the increase of the serum enzyme activity even when there is no structural liver lesion. ${ }^{18}$ Although enzyme induction may be a mechanism of an increase in GGT following chronic alcohol consumption, an enhanced release or sudden damage must also be considered when the ethanol test is applied. According to Nemewsanszki et al, ${ }^{12}$ alcoholics may have liver cells more sensitive to inductive and (or) the injurious effects of alcohol. This phenomenon could explain a significant increase in GGT as well as in the noninductable LD-5 that occurred after the ethanol challenge.

Similar to what can occur in alcoholism (increased GGT reflecting MEOS induction rather than a structural lesion), this enzyme can be increased in the plasma of those patients with a mild chronic form of schistosomiasis-that is, before the parasitosis progresses to advanced or complicated clinical forms. If the increase in serum GGT in schistosomiasis was secondary to the chronic MEOS stimulation, acute administration of ethanol could be a synergistic or potential stimulus, increasing microsomal enzyme lib- eration and, consequently, plasma concentration.

GGT values varied greatly in the group of schistosomiasis patients, the standard deviation being much higher than in the control group. This means that in spite of the criteria used for selection GGT values in the schistosomiasis group proved heterogeneous. In other words there are two populations of schistosomiasis patients with the mild form: one with a GGT of $<25 \mathrm{IU} / 1$ and another with a GGT of $>25 \mathrm{IU} / \mathrm{l}$. In the subgroup with a GGT of $<25$ IU/l the serum enzyme activity did not increase and the figures were kept below the critical level, showing that the ethanol stimulus did not have any effect on the serum GGT; this is similar to what occurs in non-alcoholic subjects. In the subgroup with a GGT of $>25 \mathrm{IU} / 1$ the stimulus did not exert any additive effect on the serum enzyme activity 24 hours after the test. These results suggest that microsomal induction is not the mechanism responsible for the increase in the serum activity of the enzyme observed in 13 of the patients with the mild form.

In alcoholic liver disease, serum ALP usually increases in a less intensive manner than GGT. ${ }^{19}$ This can mean that the effect of alcohol on the liver is to liberate a large amount of GGT in the serum, disproportionate to the amount of ALP. A significant agreement between baseline GGT and ALP was found in the 14 patients of the schistosomiasis group submitted to the ethanol test. All patients with a GGT of $<25$ IU/1 had normal ALP and, in the three cases with high ALP, GGT was also increased. As occurred with GGT, ALP did not change significantly after the test and the GGT:ALP ratio was not modified: this can indicate that the parasitosis effect on the GGT serum activity is not selective, as in alcoholism.

There are very few studies on biliary morphology in the mild chronic form of schistosomiasis, and we did not find any studies that have analysed the correlation between the intrahepatic biliary tree and serum markers of cholestasis. Significant changes in the intrahepatic biliary architecture were described in $54 \%$ of the patients with advanced parasitosis. ${ }^{20}$ Only a study analysing simultaneously the itrahepatic biliary architecture and the serum GGT activity could verify a possible correlation between these effects. We did not perform liver biopsies in our patients as this procedure was not ethically justifiable. ${ }^{21}$

These results suggest that the mechanisms reponsible for the increase in serum GGT activity in mild chronic schistosomiasis and in alcoholism are different. In the latter, microsomal induction increases the serum activity of GGT while the changes in the biliary tree could cause this increase in schistosomiasis.

1 Pooper H. Pathobiology analysis of disease mechanism: Introduction. In: Arias I, Jakoby WB, Pooper H, Schatner $\mathrm{D}$, Shafritz DA, eds. The liver biology and pathobiology. New York: Raven Press, 1988:1085.

2 Andrade AZ. Evolution and Involution of hepatosplenic schistosomiasis. Memorias do Instituto Oswaldo Cruz 1989;84:(suppl 1):58-68. 
3 Pugh RNH, Murray-Lyon IM, Dawson JL, Pietroni MC, Williams $R$. Transection of oesophagus for bleeding oesophageal varices. Br f Surg 1973;60:646-9.

4 Zwinzenberger K, Feldmeier $\mathrm{H}$, Queiroz Jan, et al. Liver involvement in human schistosomiasis. Assessment by immunological and biochemical markers. Parasitol Res 1988;74:4448-55.

5 Ramos OL, Saad F, Leser WP. Portal hemodynamics and liver cell function in hepatic schistosomiasis. Gasteroenterology 1964;47:241-7.

6 Brant PC, Prata A. Altered drug metabolism in hepatosplenic schistosomiasis. Revista do Instituto de Medicina plenic schistosomiasis. Revista do São Paulo 1979;21:254-9.

7 Manoukian N, Borges DR. Hypoprothrombinemia in the compensated form of hepatosplenic schistosomiasis: Furcompensated form of he paties. Revista do Instituto de Medicina Tropical de São ther studies. Revista do

8 Borges DR, Manoukian N, Toledo CF. Protein C deficiency in the compensated form of hepatosplenic schistosomiasis. Brasilian f Med Biol Res 1987;20:557-60.

9 Borges DR, Manoukian N. Avaliação da função hepática de sintese protêica na hepatopatia esquistossomótica compensade e na cirrose. Rev Ass Med Brasil 1987;33:3-6.

10 Rosalki SB. Gamma-glutamyl transpeptidase. Adv Cli Chem 1975;17:3-107.

11 Reichling J, Kaplan MM. Clinical use of serum enzymes in liver disease. Dig $D$ is $S c i$ 1988;33:1601-14.

12 Nemesanszky E, Lott JA, Arato $M$. Changes in serum enzimes in moderate drinkers after an alcohol challenge. Clin Chem 1988;343:525-7.

13 Hartz AJ. Overlap Index. An alternative to sensitivity and specificity in comparing the utility of a laboratory test.
Arch Pathol Lab Med 1984;108:65-8.

14 Gill GV, Baylis PH, Flear CTG, Skillen AW, Diggle HP. Acute biochemical responses to moderate beer drinking. Acute biochemical responses

15 Belfrage P, Berg B, Cronholm T. Prolonged administration of ethanol to young, healthy volunteers: effects on biochemical, morphological and neurophysiological parameters. Acta Med Scand 1973;552:1-53.

16 Luchi P, Cortis G. Forensic considerations on the comparison of serum gamma-glutamyltranspeptidase activity in experimental acute alcoholic intoxication and in alcoholic car drivers who caused road accidents. Forensic Sci 1978;11:33-40.

17 Moussavian SN, Becker RC, Piepmeyer JL, Mezey E Bozian RC. Serum gamma-glutamyl transpeptidase and
chronic alcoholism. Influence of alcohol ingestion and chronic alcoholism. Influence of alcohol

18 Tescke R, Brand A, Strohmeyer G. Induction of hepatic microsomal gamma-glutamyltransferase activity following chronic alcohol consumption. Biochem Biophys Res Commun 1977;75:718-24.

19 Lai CL, Ng RP, Lok ASF. The diagnostic value of the ratio of gamma-glutamyl transpeptidase to alkaline phosphatase in alcoholic liver disease. Scand 7 Gastroenterol 1982;17:41-7.

20 Vianna MR, Gayotto LCC, Santos TM, Alves VAF, Fukushima J, Brito T. Intrahepatic bile duct changes in human hepatosplenic schistosomiasis mansoni. Liver 1989;9: $100-9$.

21 Ireland A, Hartley L, Ryley N, et al. Raised gammaglutamyltransferase and the need for liver biopsy. $\mathrm{Br} M e d$ f 1991;302:388-9. 